BRGÖ 2020

Beiträge zur Rechtsgeschichte Österreichs

Kinga BELIZNAI BÓDI, Budapest

\title{
Die disziplinäre Verantwortlichkeit von Richtern in Ungarn in der zweiten Hälfte des 19. Jahrhunderts, mit einem Überblick über die österreichische Regelung
}

\begin{abstract}
Disciplinary Liability of Judges in Hungary in the second half of the $19^{\text {th }}$ Century, with an Overview of the legal situation in Austria

At the meeting of the Hungarian Lawyers' Association on 9 January 1889, the renowned Hungarian scholar of criminal law and judge, Károly Csemegi, emphasized the close relationship between judicial, especially disciplinary, responsibility and judicial independence. He argued that the Judicial Disciplinary Act could not be anything other than an extended version, "a corollary of judicial independence".

In April 1699, Henri François d'Aguesseau (1668-1751), attorney general of the Parliament of Paris, stipulated that the first duty of the judge must be to administer justice and the second to preserve his dignity, respect himself and venerate "the holiness of his office".
\end{abstract}

The preservation of the dignity, integrity and respect of judges is inconceivable if the judge abuses his powers, neglects his judicial duties or even violates them. A strong, well-educated and independent judiciary can function only if the legislature lays down the rules of accountability.

Until the middle of the 19th century, the general provisions on the responsibility of state or administrative officials in Hungary also applied to members of the judiciary.

Keywords: $19^{\text {th }}$ century - court system - disciplinary liability - Hungary -judicial liability

\section{Die Justizverwaltung Ungarns nach 1860}

Im Allerhöchsten Handschreiben an Graf Bernhard Rechberg in Bezug auf das am 20. Oktober 1860 gegebene Oktoberdiplom ${ }^{1}$ deklarierte Kaiser Franz Joseph: „Hinsichtlich der Justiz-Angelegenheiten und Rechtssprechung in Meinem Königreiche Ungarn bin Ich entschlossen, die königliche Kurie unter Vorsitz des Judex Curiae in Pest

\footnotetext{
${ }^{1}$ Kaiserliches Diplom vom 20. October 1860 zur Regelung der inneren staatsrechtlichen Verhältnisse der Monarchie (Oktoberdiplom, RGBl. 226/1860).

http://dx.doi.org/10.1553/BRGOE2020-1s5
}

wieder einzusetzen“. Mittels Allerhöchster Entschließung vom 7. Januar 1861 verlieh der Kaiser die Würde des Judex Curiae Regiae dem geheimen Rate György Apponyi, ${ }^{2}$ am 20. Januar wurden die Richter des Septemviralgerichts ernannt und am 1. Februar die ungarische Abteilung des Wiener Obersten Gerichtshofs aufgehoben. Die Kurie nahm am 3. April 1861 ihre Tätigkeit in feierlichem Rahmen wieder auf.

\footnotetext{
${ }^{2}$ Wiener Zeitung Nr. 10 v. 12. 1. 1861, 141.
} 
Am Anfang der 1860er Jahre stand die ungarische Regierung vor der großen Aufgabe, nach Jahren des österreichischen Neoabsolutismus ein neues ungarisches Rechtssystem zu schaffen, das sowohl in seinen Grundlagen als auch in seiner konkreten Ausgestaltung dem Stand der zeitgenössischen Rechtswissenschaft und den ungarischen Verhältnissen entsprach.

Im Juni 1867 formulierte Justizminister Boldizsár Horváth in der Sitzung des Abgeordnetenhauses: „In keinem Zweig der Verwaltung ist die Notwendigkeit von Reformen so stark zu spüren, wie in der Rechtsprechung. Die Mängel unserer Gerichtsbarkeit sind allgemein bekannt. Bisher gab es eine Entschuldigung für diese Mängel, weil die Verfassung nicht wiederhergestellt war und die Landesversammlung ihr Gesetzgebungsrecht nicht ausüben konnte. Nachdem aber die Verfassung wiederhergestellt [...] und die Landesversammlung in ihr Gesetzgebungsrecht wieder eingesetzt wurde: von diesem Moment an würde jegliches Versäumnis unserer moralischen Reputation zu Laste fallen. “3

Eine vorrangige Aufgabe der Andrássy-Regierung nach dem "Ausgleich“ bestand im Ausbau einer Staatsorganisation, die auf die bestehende Beziehung zu Österreich abgestimmt sein musste, "die Überreste“ der Gerichtsorganisation vor 1848 bewahrte, deren Eingliederung in die neue Gesellschaftsordnung unterstützte und auch die Entstehung neuer, zeitgemäßer Institutionen ermöglichte. ${ }^{4}$

Die im Dezember 1868 verkündete Ordnung der Rechtsprechung in Zivilsachen brachte eine Gerichtsorganisation nach österreichischem Muster.

${ }^{3}$ Képviselőházi napló [Journal des Abgeordnetenhauses], 1865, Bd. IV, 22. 3.-2. 7. 1865, Sitzungstage 1865141, 265.

${ }^{4}$ MÁTHÉ, A magyar burzsoá igazságszolgáltatási szervezet kialakulása 25 .

${ }^{5}$ Der Aufbau der ordentlichen Gerichtsbarkeit folgt heute dem in der bürgerlichen Zeit ausgestalteten Mo-
Allgemein zuständig waren die Stadt- und Bezirksrichter, der Stuhlrichter, die Komitats- und Stadtgerichtshöfe, die Tafelgerichte und die Kurie $^{5}$ die bis 1882 in zwei Abteilungen, als Kassationshof und als Oberster Gerichtshof, tätig war. Eine besondere Zuständigkeit hatten Marktgerichte, Wechsel- und Handelsgerichtshöfe, Berggerichte, Schiedsgerichte sowie in Ehesachen die kirchlichen Gerichte.

In seiner Thronrede anlässlich der Eröffnung der Landesversammlungssitzung am 24. April 1869 hob Franz Josef hervor, dass ,eines der ersten Erfordernisse eines geordneten Staatslebens die gute, schnelle und unvoreingenommene Rechtsprechung" sei. In Bezug auf die Umsetzung des Unabhängigkeitsprinzips und seiner Garantien bei Ausübung der richterlichen Gewalt betonte er die Notwendigkeit, „einerseits dass diejenigen, denen die Ausübung der äußerst bedeutsamen richterlichen Gewalt anvertraut ist, gegenüber Einzelnen aber auch der öffentlichen Gewalt mit allen Garantien der Unabhängigkeit ausgestattet sind, andererseits Jedermann vor Übergriffen der richterlichen Gewalt geschützt ist. [...] Meine Regierung wird Ihnen deshalb Entwürfe über die Ausübung der richterlichen Gewalt und über die richterliche Verantwortung vorlegen" ${ }^{6}$

dell: Die Rechtsprechung wird mit allgemeiner $\mathrm{Zu}$ ständigkeit von der Kurie, den Tafelgerichten, den Gerichtshöfen und den Bezirksgerichten ausgeübt. (Das Grundgesetz von Ungarn, § 25; Das Gesetz Nr. 161 von 2011 über Aufbau und Verwaltung der Gerichte, § 16). ${ }^{6}$ Képviselőházi irományok [Schriften des Abgeordnetenhauses], 1869, Bd. I, Schriftennr. 1869-1, 1-3. 


\section{Disziplinarbehandlung richterlicher Beamten in Österreich. Das Gesetz vom}

\section{Mai 1868}

Die Disziplinargerichtsbarkeit über richterliche Beamte oblag nach der Verfassung von 1867 aufgrund der Trennung von Gerichtsbarkeit und Verwaltung der Richterschaft. Das Staatsgrundgesetz vom 21. Dezember 1867 über die richterliche Gewalt ${ }^{7}$ verkündete, dass die Rechtspflege von der Verwaltung in allen Instanzen getrennt werde (Art. 14). Weiters normierte es, dass die Richter „in Ausübung ihres richterlichen Amtes selbständig und unabhängig“ seien (Art. 6) und dass sie „nur in den vom Gesetze vorgeschriebenen Fällen und nur auf Grund eines förmlichen richterlichen Erkenntnisses ihres Amtes entsetzt werden“ dürften. Auch die „Versetzung an eine andere Stelle oder in den Ruhestand wider Willen“ könne „nur durch gerichtlichen Beschluß in den durch das Gesetz bestimmten Fällen und Formen erfolgen". 8

Die Disziplinarbehandlung der richterlichen Beamten erfolgte nach den Bestimmungen des Gesetzes vom 21. Mai 1868. ${ }^{9}$ Das Richterdisziplinargesetz unterschied verschiedene Dienstkategorien und kannte insbesondere „selbstständige richterliche Beamte“. Dies waren Präsidenten, Vizepräsidenten und Räte der Gerichtshöfe sowie die Bezirksrichter und ,jene, welchen bei einem Gerichtshofe das Stimmrecht übertragen worden ist". Nur diese „selbstständigen richterlichen Beamten" waren Richter entsprechend dem Staats-

\footnotetext{
${ }^{7}$ Staatsgrundgesetz vom 21. Dezember 1867 über die richterliche Gewalt, RGBl. 144/1867.

${ }^{8}$ Diese Bestimmungen finden ,jedoch auf Uebersetzungen und Versetzungen in den Ruhestand keine Anwendung, welche durch Veränderungen in der Organisation der Gerichte nöthig werden“.
}

grundgesetz über die richterliche Gewalt. Sie waren unabhängig in Ausübung des richterlichen Amtes und durften, abgesehen von Veränderungen der Gerichtsorganisation, nur auf der Grundlage eines disziplinargerichtlichen Beschlusses versetzt werden. ${ }^{10}$ Das übrige Personal war, selbst wenn es in richterlicher Funktion tätig war, nur Hilfspersonal („Secretäre, Adjuncten, Actuare und Auscultanten"). ${ }^{11}$

Die Pflichtverletzung war entweder eine Ordnungswidrigkeit oder ein Dienstvergehen. Richterliche Beamte, welche die ihnen durch ihr Amt oder ihren Diensteid auferlegten Pflichten verletzten, wurden mit Ordnungs- oder Disziplinarstrafen belegt, je nachdem, ob sich die Pflichtverletzung als eine bloße Ordnungswidrigkeit, oder mit Rücksicht auf die Art und den Grad derselben, auf die eventuelle Wiederholung und die erschwerenden Umstände, als ein Dienstvergehen darstellte. $\mathrm{Zu}$ den Pflichten der richterlichen Beamten gehörte auch, dass sie sich durch ihr Verhalten im Amt oder außerhalb des Amtes der Achtung und des Vertrauens, die ihr Beruf erforderte, nicht unwürdig zeigten.

In der Spezialdebatte vom 18. März 1868 bemängelte der Abgeordnete Leopold von Mende (Niederösterreich) den materiellen Teil des Gesetzes. Es würde, „weil dieser Theil mangelt, weil darin nicht ausgesprochen ist, diese und jene Handlung bildet den Thatbestand der Ordnungswidrigkeit, diese und jene Handlung bildet den Thatbestand eines Dienstvergehens [...] eine Vagheit in das Gesetz hineingebracht, und wird einer willkürlichen Auffassung das Thor geöffnet". Er fügte hinzu: „wenn nun nicht gesagt wird,

\footnotetext{
${ }^{9}$ Gesetz vom 21. Mai 1868, betreffend die Disciplinarbehandlung richterlicher Beamten und die unfreiwillige Versetzung derselben auf eine andere Stelle oder in den Ruhestand, RGBl. 46/1868.

${ }^{10} \mathrm{KOHL}$, Zur Entwicklung der richterlichen Unabhängigkeit 22.

${ }^{11} \mathrm{KOHL}$, Richter in der Habsburgermonarchie 73-74.
} 
wodurch das Eine, wodurch das Andere geschehen kann, so ist es für den Richter, der urtheilen soll, einerseits außerordentlich schwer zu urtheilen, anderseits wird [...] der Willkür in der Beurtheilung das Thor geöffnet" ${ }^{\prime 2}{ }^{12}$ Justizminister Dr. Eduard Herbst legte dar, dass eine Formulierung des Begriffs des Dienstvergehens „nämlich einfach nicht möglich" war. "Sonst aber müssen eben die Gerichte beurtheilen, ob die zur Last gelegten Handlungen solche sind, durch welche dem Amte und den beschworenen Dienstpflichten zuwider gehandelt wurde, ob die Handlungsweise eine solche sei, wodurch die Achtung, die mit der Erfüllung der Amtspflicht verbunden sein soll, verwirkt worden ist. ${ }^{\text {13 }}$ Berichterstatter Dr. Ritter von Kremer stimmte bei, dass in der Regierungsvorlage nur ein allgemeiner Satz aufgestellt wurde. „Ich glaube daher $[. .$.$] daß viel-$ mehr das Hauptgewicht auf zwei andere Momente zu legen wäre, nämlich auf das Gericht, welches über solche Fälle zu entscheiden hat, welchem die discretionäre Gewalt bezüglich der Anwendung des allgemeinen Satzes überlassen ist und andererseits auf das Verfahren in diesen Gerichten. “14

Auf Ordnungswidrigkeiten war mit Ordnungsstrafen, Mahnung und Verweis zu reagieren. Die "Mahnung“ wurde statt der "Rüge“ als mindeste Ordnungsstrafe aufgenommen, weil dieses Wort den Unterschied zum „Verweis“ und die geringere Strafwürdigkeit des Falles auf eine sprachlich richtigere Weise bezeichne. ${ }^{15}$ Justizminister Herbst betonte, dass die Mahnung eigentlich nichts anderes „als ein nothwendiger Ausfluß des Leitungsrechtes des Gerichtsvorstehers", und "nur ganz uneigentlich unter den Begriff ,Ordnungsstrafe' subsumiert" sei.16 Gegen eine Mahnung war kein Rechtsmittel zulässig, doch schon gegen einen Verweis hatte der richterliche

\footnotetext{
${ }^{12}$ StenProt. AH, 4. Sess., 79. Sitzung, 18. 3. 1868, 22132217.

13 Ebd. 2214.

14 Ebd. 2215.
}

Beamte ein Beschwerderecht an die obere Instanz. ${ }^{17}$

Die Disziplinarstrafen waren die folgenden: a) Versetzung an einen anderen Amtssitz ohne Rangverminderung, wobei der Versetzte die Übersiedlungskosten selbst zu tragen hatte; b) Versetzung in den Ruhestand auf unbestimmte Zeit mit Verminderung der normalmäßigen Ruhestandsgenüsse; c) Dienstentlassung mit Verlust des Titels und Pensionsanspruches. Solche Disziplinarstrafen konnten gegen richterliche Beamte nur von den zuständigen Disziplinarsenaten nach gesetzmäßig durchgeführter Verhandlung ausgesprochen werden. Die Disziplinarsenate waren ständige, beim Obersten Gerichtshof und jedem Oberlandesgericht nach Vorschrift des Gesetzes mit Anfang jedes Jahres für die ganze Dauer desselben zusammengesetzte Ratskollegien. Das Verfahren war nach den Grundsätzen des mündlichen Anklageprozesses geregelt, und dem Beschuldigten stand gegen das Erkenntnis des Disziplinarsenates beim Oberlandesgericht die Appellation an den Disziplinarsenat des Obersten Gerichtshofs zu. ${ }^{18}$ War das Disziplinargericht der Meinung, dass die einem richterlichen Beamten zur Last gelegte Pflichtverletzung nach dem allgemeinen Strafgesetze zu ahnden wäre, so hatte es Anzeige beim zuständigen Strafgericht zu erstatten.

\section{Die Verantwortlichkeit von Richtern und richterlichen Beamten in Ungarn. Das Gesetz Nr. 8 von 1871}

Die Regeln über die Verantwortlichkeit von Richtern, die in Ungarn durch § 24 des Gesetzes Nr. 4

\footnotetext{
${ }^{15}$ Ebd. 2216.

${ }^{16}$ Ebd. 2217.

${ }^{17}$ GUMPLOWICZ, Österreichisches Staatsrecht 192.

18 Ebd. 193.
} 
von 1869 über Ausübung der richterlichen Gewalt einem selbstständigen Gesetz vorbehalten wurde, waren im Gesetz Nr. 8 von 1871 enthalten.

In der Sitzung des Magnatenhauses am 10. Dezember 1869 kam Justizminister Boldizsár Horváth, der die Gesetzesvorlage einbrachte, darauf $\mathrm{zu}$ sprechen, dass die wichtigste $\mathrm{zu}$ beantwortende Frage im Laufe der Erarbeitung des Gesetzes sei, „[i]n welchen Fällen der Richter der Verantwortlichkeit untersteht?", denn „wegen womöglich fehlerhafter Lösung einer Rechtsfrage oder womöglich fehlerhafter Anwendung eines Gesetzes kann der Richter coram foro fori“ nicht zur Verantwortung gezogen werden, da er „dafür nur Gott und dem eigenen Gewissen Rechenschaft schuldet“. Er fügte noch hinzu, dass „die Verantwortlichkeit auf dieses Gebiet nicht verlagert werden kann, denn dann müsste über den obersten Richter ein anderer Richter gestellt werden", und "dadurch entstünde ein unendlicher Rechtsweg, sozusagen eine Jakobsleiter, die ohne Ende in den Himmel reichte, ohne dass man am Ende des Weges einem beruhigenden Endurteil des Himmels begegnete“. Richter könnten nur für Taten oder Unterlassungen zur Verantwortung gezogen werden, „die schon wegen ihrer andersgearteten Natur die Immunität der subjektiven Auffassung nicht in Anspruch nehmen können. Außerdem ist der Richter verantwortlich für die Verletzung von Gesetzen oder Verordnungen, bezüglich derer, obwohl [...] subjektive Ansichten voneinander abweichen können, aber die vorliegenden Umstände handgreiflich bestätigen, dass der Richter in seinem Tun oder Unterlassen nicht seiner Überzeugung oder seinem Gewissen, sondern der Stimme niederer Instinkte gefolgt ist". ${ }^{19}$

Das beschlossene Gesetz besagte, dass Richter und richterliche Beamte für vorsätzliche oder schuldhaft fahrlässige Verletzungen ihrer Amtspflichten verantwortlich seien und dementsprechend für Schäden einzustehen hätten, die sie durch die Verletzung ihrer Amtspflichten verursacht hatten. Eine Straftat im Amt lag vor, wenn ein Richter seine Amtspflicht „vorsätzlich oder fahrlässig" verletzt hatte, um dadurch sich oder Dritten einen unberechtigten Gewinn zu verschaffen, oder jemandem rechtswidrig einen Schaden zuzufügen. Straftaten im Amt waren insbesondere die Verletzung der Verschwiegenheitspflicht, Bestechlichkeit, Erpressung, Gewalt, Fälschung und Veruntreuung. Richter, die ihre Amtspflicht vorsätzlich verletzten, wurden im ordentlichen Strafverfahren zur Verantwortung gezogen und außer der im Gesetz vorgegebenen Strafe zum Amts- und Titelverlust, zum Verlust der Amtsbezüge und Pension, und allgemein zum Verlust jeglicher Ansprüche auf sonstige, ihnen für ihre Dienste zustehende Vergütungen verurteilt.

Ein Disziplinarvergehen beging der Richter, der seine Amtspflicht schuldhaft, jedoch nicht „mit dem strafbaren Ziel“" verletzte, sich oder Dritten einen unberechtigten Gewinn $\mathrm{zu}$ verschaffen oder jemandem rechtswidrig einen Schaden zu verursachen, sowie der Richter, der wegen seines skandalösen Verhaltens „der Ehre und des Vertrauens unwürdig“" wurde. Die Strafe für ein Disziplinarvergehen war abhängig von der Tatschwere, einer allfälligen Wiederholung und den daraus entstandenen Nachteilen, und sie konnte Rüge, Verweis, Geldstrafe oder Amtsverlust sein. Über Disziplinarvergehen urteilten Disziplinargerichte, das bedeutete praktisch, dass über einen Richter immer das Gericht der nächsthöheren Instanz urteilte. Boldizsár Horváth begründete das einerseits damit, dass Disziplinarvergehen unmöglich abschließend aufgezählt werden

${ }^{19}$ Főrendiházi napló [Journal des Herrenhauses], 1869, Bd. I, 24. 4. 1869-3. 8. 1870, Sitzungstage 1869-24, 105106. 
können und es deshalb unerlässlich sei, das Gericht „mit gewisser discretionaler Macht auszustatten“. Er fügte auch hinzu, dass Disziplinarvergehen häufig so geringfügig seien, dass sie nur mit einem Verweis geahndet würden. So sollten sie „um das richterliche Ansehen zu wahren nie vor die Instanz des Schwurgerichts kommen”. Und sein drittes Argument war: „Ich konnte die Rechtsprechung nicht in die Hand derer geben, die mit dem Angeklagten in collegialer Beziehung stehen und gegen die dann in jedem einzelnen Fall die dringende Besorgnis der Befangenheit bestünde, weil alle Sympathien und Antipathien, die gewöhnlich in Folge von längerem Zusammensein entstehen, diejenige Unbefangenheit und Unvoreingenommenheit in den Hintergrund drängen würden, die das hauptsächliche und grundsätzliche Zubehör der Rechtsprechung sind. ${ }^{20}$

Die Unabhängigkeit des Disziplinargerichts wurde durch die Besetzung im Wege von Losziehung garantiert. In Sachen von Gerichtsbeamten an den königlichen Gerichtshöfen urteilten die erstinstanzlichen königlichen Gerichtshöfe als Disziplinargerichte. Über Disziplinarsachen von Spruchrichtern der erstinstanzlichen königlichen Gerichtshöfe befand das fünfköpfige Disziplinargericht des königlichen Tafelgerichts, in dessen Sprengel der Sitz des Gerichts war. In Disziplinarverfahren gegen Vorsitzende der erstinstanzlichen königlichen Gerichtshöfe sowie gegen Richter der königlichen Tafelgerichte übte das siebenköpfige Disziplinargericht des Obersten Gerichtshofs die Disziplinargewalt aus.

In Disziplinarsachen gegen Vorsitzende und Vizevorsitzende der königlichen Tafelgerichte, sowie gegen Vorsitzende, Vizevorsitzende und

\footnotetext{
${ }^{20}$ Ebd. 106.

${ }^{21}$ Kaiserliche Verordnung vom 12. März 1859, betreffend die Haftung für das Verschulden der Gerichtsbeamten und die Behandlung der Syndikatsbeschwerden, RGB1. 46/1859.
}

Spruchrichter der Kurie ging ein besonderes Disziplinargericht vor. Dieses selbstständige Disziplinargericht bestand aus 36 ordentlichen und 12 Ersatzmitgliedern, deren eine Hälfte vom Oberhaus der Landesversammlung und die andere Hälfte von den Vizevorsitzenden und Richtern der Kurie ausgewählt wurde. Den Vorsitz im Disziplinargericht führte der Vorsitzende oder der Vizevorsitzende des Oberhauses. Die Mitglieder des Oberhauses hatten den richterlichen Eid zu leisten. Das Disziplinargericht ging als zwölfköpfiger Spruchkörper vor, gegen seinen Beschluss war keine Berufung statthaft.

Zufolge des Gesetzes Nr. 8 von 1871 hafteten Richter und Gerichtsbeamten auch für Schäden, die durch die Verletzung ihrer Amtsplichten verursacht wurden. In Bezug auf die Haftung auf Schadenersatz wurden in der ungarischen Regelung Bestimmungen der österreichischen kaiserlichen Verordnung vom 12. März 185921 übernommen.

Wenn ein Richter oder ein Gerichtsbeamter bei der Justizverwaltung vorsätzlicher oder fahrlässiger Weise einer Partei durch die Verletzung oder Vernachlässigung seiner Amtspflicht Schaden zufügte, so wurde er, sofern durch die gesetzlichen Rechtsmittel eine Abhilfe nicht gewährt werden konnte, zu voller Schadloshaltung verpflichtet.

Die Entschädigungsansprüche der Parteien mussten mittels eines besonderen Gesuches beim Disziplinargericht eingereicht werden. Der Antrag musste die pflichtwidrige Handlung oder Unterlassung genau und ausführlich beschreiben. ${ }^{22}$ Die Schadenersatzklage wurde im Zivilprozess beurteilt, vorausgesetzt, dass die schadenverursachende Handlung oder Unterlassung nicht Gegenstand eines Strafverfahrens war.

\footnotetext{
${ }^{22}$ CSÁNK, A bírói függetlenség 222.
} 
In Österreich begründete das Staatsgrundgesetz vom 21. Dezember 1867 die Haftung des Staates auf Schadenersatz. Laut Art. 9 des Gesetzes konnte der Staat wegen der von den Richtern oder den Gerichtsbeamten in Ausübung ihrer amtlichen Wirksamkeit verursachten Rechtsverletzungen mittels Klage belangt werden. Dieses Klagerecht wurde einige Jahre später durch das Gesetz vom 12. Juli $1872^{23}$ geregelt. Auch in Ungarn sah das Gesetz Nr. 8 von 1871 die Haftung des Staates auf Schadenersatz vor. Der Staat haftete für alle Schäden, die den Parteien durch Amtsunterschlagung von Richtern oder richterlichen Beamten entstanden waren.

\section{IV. Änderung des Gesetzes über die disziplinäre Verantwortlich- keit der Richter im Jahre 1888}

Die „Unzulänglichkeiten“ des Gesetzes Nr. 8 von $1871 \mathrm{zu}$ heilen, versuchte die vom Justizminister Teofil Fabiny am 5. November 1888 eingebrachte, von der Landesversammlung jedoch nicht auf die Tagesordnung gesetzte Gesetzesvorlage. Als Mängel des Gesetzes wurden gesehen: Es definierte den Tatbestand der einzelnen Disziplinarvergehen jeweils nicht exakt genug, überließ die

\footnotetext{
${ }^{23}$ Gesetz vom 12. Juli 1872, womit zur Durchführung des Artikels 9 des Staatsgrundgesetzes vom 21. Dezember 1867 über die richterliche Gewalt, das Klagerecht der Parteien wegen der von richterlichen Beamten in Ausübung ihrer amtlichen Wirksamkeit zugefügten Rechtsverletzungen geregelt wird RGBl. $112 / 1872$.

${ }^{24}$ Indokolás „a bírák és bírósági hivatalnokok felelősségéről, valamint az ezzel összefüggő kérdések szabályozásáról” intézkedő törvényjavaslathoz [Begründung zur Gesetzvorlage „über die Verantwortlichkeit von Richtern und richterlicher Beamten und die Regelung damit zusammenhängender Fragen"], in: Képviselőházi irományok [Schriften des Abgeordnetenhauses], 1887, Bd. IX, Schriftennr. 1887-305, 202217, hier 202.
}

Besetzung des Disziplinargerichts der „Zufälligkeit“ des Loses, regelte das Beschwerde-bzw. das Anklagerecht weder von Privatpersonen noch von Behörden exakt und die Regeln des Disziplinarverfahrens würden den Erfordernissen weder der "gerechten Strenge" noch der Schnelligkeit genügen. ${ }^{24}$

Der Gesetzesentwurf von 1888 behandelte nicht die Bestimmungen des Gesetzes von 1871 über die Straftaten im Amt. Straftaten im Amt wurden durch das 1880 in Kraft getretene Strafgesetzbuch (Gesetz Nr. 5 von 1878), den sogenannten Csemegi-Kodex, geregelt. ${ }^{25}$

Laut Gesetzesentwurf begeht der Richter ein Disziplinarvergehen, wenn er seine Amtspflicht nicht oder nachlässig erfüllt. Diese Bestimmung stand nicht in Einklang mit dem Strafgesetzbuch, dessen $\S 480$ besagte, einen Amtsmissbrauch begehe, wer die Erfüllung seiner Amtspflicht verweigert. Die Definition in der Vorlage war ungenau, denn es fehlte darin die Definition, was ein Disziplinarvergehen vom Vergehen laut StGB unterscheidet, dass nämlich der Richter seine Amtspflicht mit dem Ziel schuldhaft verletzt, sich oder Dritten einen unberechtigten Vorteil zu verschaffen, bzw. einem Dritten rechtswidrig Schaden zu verursachen. ${ }^{26}$

\footnotetext{
${ }^{25}$ Gemäß § 468 des Gesetzes Nr. 5 von 1878 sollte „einem Richter [...] die gleiche Strafe verhängt werden, wenn er seine Amtspflicht zwar nicht verletzt, aber für sein ihm von Amts wegen obliegendes Tun oder Unterlassen ein Geschenk oder Belohnung verlangt, annimmt, oder ein diesbezügliches Versprechen nicht abweist, und dies sogar in Fällen, wenn das Geschenk oder die Belohnung mit seiner Zustimmung Dritten gewährt oder versprochen wurde".

Mit Gefängnisstrafe von fünf bis zehn Jahren ist ein Richter zu bestrafen, „der im Zivil- oder Strafprozess, in dem er bestochen wurde, gesetzwidrig geurteilt oder einen Beschluss gefasst hat" (§ 469).

${ }^{26}$ SZÉKELY, A bírák és bírósági hivatalnokok felelősségéről szóló törvényjavaslat 68.
} 
Im Sinne der Vorlage lag ein Disziplinarvergehen vor, wenn der Richter seine Amtspflicht vorsätzlich oder fahrlässig verletzte, wenn er durch sein Verhalten das Ansehen seines Amtes beschädigte oder sich skandalös verhielt, außerdem, wenn er seinen Amtssitz ohne Zustimmung seines Vorgesetzten verließ, oder wenn er nach Ablauf der ihm gewährten Ferien oder des Urlaubs nicht an seinen Amtssitz zurückkehrte.

Ein neues Element in der Vorlage war, dass sie es einem Disziplinarvergehen gleichsetzte, wenn die Bezüge eines Richters oder eines Gerichtsbeamten - wegen leichtsinniger und verschwenderischer Lebensführung - in der Höhe eines Jahresgehalts für länger als sechs Monate gerichtlich gepfändet wurden. Diese Bestimmung hätte nur für Personen gegolten, die durch ihre leichtsinnige und verschwenderische Lebensführung, also aus eigenem Verschulden, in "den Sog des materiellen Ruins" gezogen worden waren. Von ihnen könne keine zuverlässige Wahrnehmung öffentlicher Angelegenheiten, nicht die restlose Erledigung ihrer Amtsaufgaben, insbesondere „keine beruhigende“ Urteilsfindung als Richter erwartet werden. ${ }^{27}$

Die Vorlage enthielt wesentliche Neuerungen bezüglich der Disziplinarstrafen. Einerseits fehlte in ihr die durch das Gesetz von 1871 geregelte Rüge, andererseits legte sie auch neue Strafarten fest. Sie ermöglichte die Verhängung eines schriftlichen Verweises bzw. einer Geldstrafe und außerdem die Nichtberücksichtigung von Dienstzeiten bei Festlegung der Höhe der Pension oder der Abfindung, außerdem die Versetzung, die Zwangspensionierung bzw. den Amtsverlust.

\footnotetext{
${ }^{27}$ Indokolás „a bírák és bírósági hivatalnokok felelősségéről, valamint az ezzel összefüggő kérdések szabályozásáról" intézkedő törvényjavaslathoz [Begründung zur Gesetzvorlage „über die Verantwortlichkeit von Richtern und richterlicher Beamten und die Regelung damit zusammenhängender Fragen"],
}

Zur Versetzung als Disziplinarstrafe hätte es gemäß Vorlage kommen können, wenn zum Disziplinarvergehen dem Schuldigen die an seinem Amtssitz bestehenden Verhältnisse oder Umstände Gelegenheit oder Ursache lieferten, oder wenn das Ansehen des Richters oder des Gerichtsbeamten durch das begangene Disziplinarvergehen dermaßen untergraben wurde, dass „eine erfolgreiche Tätigkeit auf seinem bisherigen Sitz von ihm nicht zu erwarten ist" ${ }^{28}$ Die Zwangspensionierung hätte verhängt werden können, wenn der in Konkurs geratene Richter oder Gerichtsbeamte nachweisen konnte, dass er nicht wegen seiner leichtsinnigen oder verschwenderischen Lebensführung zum „Gemeinschuldner" wurde.

Die Gesetzesvorlage befasste sich eingehend mit den moralischen Wirkungen und Folgen der Disziplinarstrafen. Zum Beispiel hatte ein Richter, der zum Amtsverlust verurteilt wurde, fünf Jahre lang keinen Rechtsanspruch auf eine Beförderung. Eine diesbezügliche Regelung fehlte im Gesetz von 1871

In der Aufzählung der Disziplinarstrafen im Entwurf fehlte zwar die Rüge, aber wegen geringfügiger Verletzung der Amtspflichten oder wegen unanständigen Verhaltens konnte der Gerichtsvorsitzende - ohne Disziplinarverfahren - gegen den Richter oder den Gerichtsbeamten eine Mahnung oder Rüge aussprechen. Laut Begründung der Vorlage seien Mahnung und Rüge keine Disziplinarstrafen, sondern sie hätten „den Charakter eines Verwaltungszuchtmittels". ${ }^{29}$

Konrád Imling, Richter am Budapester königlichen Tafelgericht, war der Ansicht, dass es schwierig sei, zwischen dem "unanständigen“ und dem „skandalösen Verhalten“ eines Richters

in: Képviselőházi irományok [Schriften des Abgeordnetenhauses], 1887, Bd. IX, Schriftennr. 1887-305, 202 217, hier 205.

${ }^{28}$ Ebd. 206.

${ }^{29}$ Ebd. 208. 
zu unterscheiden, denn „niemand kann a priori, ohne Kenntnisse über den konkreten Fall und seine Umstände, sagen, wann das Verhalten eines Menschen aufhört unanständig zu sein und beginnt, skandalös zu werden“. ${ }^{30}$

Nach dem Muster des österreichischen Gesetzes von 1868 brachte die ungarische Vorlage von 1888 als Neuigkeit, dass ein Richter oder Gerichtsbeamter von seiner Stelle suspendiert werden müsse, wenn er seinen Amtssitz ohne Erlaubnis verlassen hatte und trotz Aufforderung nicht zurückgekehrt war, und dabei die Ursache seiner Abwesenheit nicht nachgewiesen oder seinen Aufenthaltsort verheimlicht hatte. ${ }^{31}$

Der Gesetzentwurf wurde mehrfach kritisiert, insbesondere wegen der im Entwurf verwendeten Ausdrücke, wie "das Ansehen der Stelle verletzendes Verhalten“, „Untergraben des richterlichen Ansehens", ,"Nachlässigkeit" , "leichtsinnige und prunkvolle" oder "verschwenderische Lebensführung“. Die Kritik wies auf die Ungenauigkeit und auf unterschiedliche Auslegungsmöglichkeiten dieser unbestimmten Gesetzesbegriffe hin, was „einen günstigen Anlass und Vorwand für Einflussnahme" bieten könne und dadurch die richterliche Unabhängigkeit gefährde. ${ }^{32}$

Die Geltung des Gesetzes Nr. 8 von 1871 hatte sich auf alle Richter, auf das Hilfspersonal der Gerichte, auf die bei den Gerichten tätigen Staatsanwälte und auf den Kronanwalt, auf das Verwaltungspersonal sowie auf die ständigen Sachverständigen der Gerichte erstreckt. Die Geltung des Gesetzes wurde 1881 auch auf die Richter des Börsengerichts, dann 1896 auf die Richter des neu aufgestellten Verwaltungsgerichts, später auf die Gerichtsvollzieher, und schließlich 1933 auf die Richter und Gerichtsbeamten des Patentgerichts ausgedehnt.

\footnotetext{
${ }^{30}$ IMLING, Észrevételek 390.

${ }^{31}$ Törvényjavaslat a bírák és bírósági hivatalnokok felelősségéről, valamint az ezzel összefüggő kérdések szabályozásáról [Gesetzvorlage über die Verantwortlichkeit von Richtern und richterlichen Beamten und
}

Welche Einflüsse bzw. Konzeptionen waren im Gesetz von 1871 und in der Gesetzesvorlage von 1888 bei den Bestimmungen über die richterliche Verantwortlichkeit zum Tragen gekommen? Obwohl das Gesetz von 1871 und der Entwurf von 1888 im Prinzip der Grundkonzeption des österreichischen Richterdisziplinargesetzes von 1868 folgten, gab es einige Unterschiede.

Das Richterdisziplinargesetz von 1868 regelte ausführlich die unerlaubte Entfernung richterlicher Beamten vom Amte (\$§ 37-38). Im Gegensatz zu den österreichischen Bestimmungen betrachtete die ungarische Vorlage von 1888 die unbefugte Abwesenheit lediglich als Disziplinarvergehen und befasste sich nur mit dem Fall, der mit Amtsverlust sanktioniert werden konnte. Andere Fälle blieben ungeregelt.

Wie erwähnt, ging in Ungarn ein besonderes Disziplinargericht gegen Vorsitzende und Vizevorsitzende der königlichen Tafelgerichte bzw. der Kurie vor. Dieses Gericht bestand aus 36 ordentlichen Mitgliedern, deren eine Hälfte vom Oberhaus der Landesversammlung und die andere Hälfte von den Vizevorsitzenden und Richtern der Kurie ausgewählt wurde.

Rechtswissenschaftler und Juristen sahen darin eine Verletzung der richterlichen Unabhängigkeit und hielten es für keine gute Lösung, Mitglieder der Legislative mit Disziplinargerichtsbarkeit in Sachen der obersten Richter zu betrauen. Am Ende des 19. Jahrhunderts drängten sie darauf, dem österreichischen Beispiel zu folgen, bei dem das zuständige Disziplinargericht für die Präsidenten und Vizepräsidenten der Gerichtshöfe der Oberste Gerichts- und Kassationshof bzw. das Oberlandesgericht waren.

die Regelung damit zusammenhängender Fragen], in: Képviselőházi irományok [Schriften des Abgeordnetenhauses], 1887, Bd. IX, Schriftennr. 1887-305, 174201, hier 195.

32 A bírói felelősség rendszere 407. 


\section{Rechtsfälle im Bereich der disziplinären Verantwortlichkeit von Richtern ${ }^{33}$}

\section{Ein kleiner Skandal am königlichen Tafelgericht zu Szegedin [Szeged]}

Im Sommer 1891 veröffentlichte Géza Káplány, Richter am königlichen Tafelgericht zu Szegedin [Szeged] im Ügyvédek Lapja (Anwaltsblatt) einen offenen Brief gegen den Vorsitzenden des Gerichts, Sándor Sélley. Es geschah nämlich, dass Sélley am 27. August 1891 Géza Káplány und zwei weitere Richter zu sich kommen ließ. Als die drei das Zimmer des Vorsitzenden betraten, bot er ihnen keinen Platz an und forderte sie „in einem Ton und einer Manier", „wie ein gebildeter Mensch nicht einmal mit seinem Diener spricht", auf, „mit solch einer liederlichen Fetzenarbeit nie mehr herzukommen", sonst werde er gegen sie ein Disziplinarverfahren einleiten. Géza Káplány hielt das unrechtmäßige Verfahren für eine Verletzung des richterlichen Selbstgefühls, und da er vergeblich auf die Rücknahme der unbeherrschten Worte gewartet hatte, trug er die Beleidigung an die Öffentlichkeit.

,[...] seine Gnaden hätte gern, wenn alle seiner Richter so gut und so viel arbeiten könnten wie er. Aber es gibt nur einen Sélley auf der Welt. Zu der verwunderlichen Leistung, wie er damals als Richter in einem Jahr 1200 Sachen erledigt hat, ist kein Normalsterblicher fähig, denn wenn er versuchen würde, ihm nachzuahmen, würde er dabei entweder wahnsinnig oder daran sterben", schrieb Káplány. Er führte langatmig aus, dass er selbst täglich sechs, aber häufig acht bis zehn Stunden mit Arbeit verbringe. In dieser Zeit erledige er nicht nur verwickelte Grundbuchsachen,

\footnotetext{
${ }^{33}$ Die Details der hier diskutierten Rechtsfälle stammen aus Tageszeitungen, juristischen Zeitschriften, Entscheidungssammlungen der Gerichtshöfe und $\mathrm{Ku}-$ rienprotokollen. Rechtsakten und Gerichtsurteile sind nur unvollständig in Staats- und Landesarchiven zu
}

sondern er lese juristische Bücher und lerne, und sei sogar „in der Rechtsliteratur tätig“. „Kann ich dafür bestraft werden, dass ich nach 22 Jahren lästigen Dienstes jetzt nicht mehr so viel arbeiten kann wie in meiner Jugend?", stellte er die Frage. Er bemerkte auch: „Andere grübeln vielleicht nicht so viel. Aber ich habe keine Ruhe, bis ich von $\mathrm{A}$ bis $\mathrm{Z}$ nicht alles durchgeschaut, nicht alles gelesen habe, und in meinem Gehirn nicht alles von jeder Seite betrachtet habe." Bezüglich der „liederlichen Fetzenarbeit“ schrieb er: „Wären meine Arbeiten liederlich und nichts wert, würden die meisten meiner Meinungen nicht einstimmig durchgehen; meine Arbeiten würden nicht so sauber nach der Revision meines Gerichtsvorsitzenden da stehen, dass nur an wenigen etwas geändert wurde. ${ }^{\text {“34 }}$

Gegen Géza Káplány wurde ein Disziplinarverfahren eingeleitet, seine Sache wurde im Mai 1892 vom Disziplinarsenat der Kurie verhandelt. Ihm wurde "skandalöses Verhalten“ vorgeworfen. Káplány verteidigte sich, er habe seinen Vorsitzenden nicht auf dem gewöhnlichen Wege verklagen wollen, um „sein Ansehen dadurch nicht zu untergraben". Sélley aber berief sich darauf, dass der Richter seine Pflicht nur mit Ach und Krach erfüllt habe, von Mai bis Ende August lediglich 39 Sachen erledigt habe, sodass es kein Wunder sei, dass der Rückstand „,in erschreckendem Maße" zugenommen habe. Der Verteidiger von Káplány bemühte sich zu beweisen, dass die Veröffentlichung des offenen Briefes den Begriff "des skandalösen Verhaltens" nicht erfüllte. Skandalöses Verhalten eines Richters bedeute, dass er ein Säufer sei, leidenschaftlich Karten spiele oder aber „schmutzige“ Schulden anhäufe, diese Taten seien nämlich geeignet, den Richter

finden. Bei der Darstellung der Rechtsfälle habe ich versuchte, die dazugehörigen Artikel objektiv zusammenzufassen.

${ }^{34}$ Csöndélet a szegedi kir. táblánál 12-13. 
„der Ehre und des Vertrauens unwürdig“ zu machen. Aber Káplány habe keine dieser Verfehlungen begangen.

Der Disziplinarsenat sprach Géza Káplány trotzdem schuldig und sprach eine Rüge aus. Die Begründung lautete: „Der angeklagte Tafelrichter ließ außer Augen, als er seinen Artikel schrieb, dass er den erlittenen Beleidigungen auf gesetzlichem Wege hätte Heilung verschaffen können, und er vergaß sich dermaßen, dass er seinen Affekt nicht im Zaum halten konnte und deshalb ein Verhalten an den Tag legte, das das Vertrauen in ihn ins Wanken bringen konnte. ${ }^{\prime 35}$

\section{Ein Bezirksrichter, der eine Tischlerwerkstatt betrieb}

Im Frühjahr 1908 wurde der Justizminister Antal Günther in einem Brief ohne Unterschrift darüber informiert, dass Kálmán Vitális, Leiter des Bezirksgerichts zu Neuhäusel in der Liptau [Liptovský Hrádok, Liptóújvár] im Gebäude des Bezirksgerichts eine Tischlerwerkstatt eingerichtet habe. In der Werkstatt ließ er die Gefangenen die von ihm erfundenen und patentierten Bienenstöcke unter Aufsicht des Gefängniswärters anfertigen. Die Bienenstöcke veräußerte er dann zu einem guten Preis.

Der anonyme Briefschreiber beschuldigte den Bezirksrichter außerdem, zwei Amtsdiener ihrer täglichen Arbeit im Amt zu entziehen und sie mit Erledigung seiner Privatsachen zu beschäftigen, und wenn der Richter Gäste habe, müssten die Amtsdiener am Tisch servieren.

\footnotetext{
${ }^{35} \mathrm{~A}$,,szegedi cikk" 11.

${ }^{36}$ A járásbíró találmánya 20.

${ }^{37}$ In der bürgerlichen Zeit wurde der früher verwendete Ausdruck „waghalsiges Prozessieren” durch die Institution des sog. hartnäckigen Prozessierens abgelöst. Dieser Ausdruck erschien erstmals im Gesetz Nr. 26 von 1723, aber erläutert wurde er erst in der Ordnung der Rechtsprechung in Zivilsachen (Gesetz Nr. 54 von 1868). Als hartnäckiger Prozessierer galt gemäß Gesetz eine Prozesspartei, die gegen zwei gleichlautende Urteile eine weitere Berufung einlegte, wenn
}

Die Ermittlung in der Disziplinarsache befand die Vorwürfe für begründet, und Kálmán Vitális erhielt eine Rüge. ${ }^{36}$

\section{3. „Auf überflüssiges Geschnörkel, auf Gerede und sinnloses Mäkeln habe ich keine Antwort“}

Antal Laczkó, den Unterbezirksrichter zu Budapest, hielt man für eine hervorragende Persönlichkeit im Auftreten gegen eingefleischte Querulanten $^{37}$. Seine störrische, freimütige Natur brachte ihn aber vielmals in peinliche Situationen. Einer dieser Fälle ereignete sich im Mai 1903, als er sich mit dem Beklagten des vor ihm laufenden Prozesses, dem Rechtsanwalt Ernő Spicher, in ein Duell verwickelte. Laczkó war der Ansicht, dass der Anwalt ,dreist gelogen“ habe. Für diese Aussage ließ Spicher den Unterbezirksrichter noch am gleichen Tag "provozieren“, und das Duell endete mit einem Sieg von Antal Laczkó, weil er auch mit dem Säbel gut umgehen konnte.

Der auch mit seinen Vorgesetzten ständig in Verwicklungen geratene Unterbezirksrichter hatte im Januar 1904 vor dem Disziplinarsenat des Budapester königlichen Tafelgerichts zu erscheinen, wo er zweier Sachen beschuldigt wurde. Es wurde ihm vorgeworfen, angewiesene Beträge „vorschriftswidrig bestückt und ordnungswidrig statt der Staatskasse an die Landeskasse" geschickt zu haben. Als ihn der Leiter des Bezirksgerichts darauf schriftlich verwies, antwortete er: „Auf überflüssiges Geschnörkel, auf Gerede und sinnloses

sein Antrag auch in der dritten Instanz abgewiesen wurde, und das Gericht zugleich befand, dass der Antragsteller entgegen dem klaren Sinn des Gesetzes, bzw. um den Richter oder seinen Gegner zu schikanieren die Beendigung des Prozesses verhinderte. In solchen Fällen konnte der Betreffende mit Geldstrafe bis zu 300 - später sogar 1000 - Forint bestraft werden. 
Mäkeln habe ich keine Antwort, aber wenn ich eine hätte, würde ich sie verschweigen.“"38

Der andere Vorwurf bezog sich darauf, dass er gegenüber Prozessparteien und ihren Anwälten mündlich und schriftlich unanständige Worte benutzt habe, so „ließ er unter anderem einen namhaften Anwalt in einem Beschluss wissen, was er sage, sei grobes Unwissen seitens der Partei“.

In der Disziplinarverhandlung verlangte der stellvertretende Oberstaatsanwalt für Antal Laczkó gemäß Gesetz Nr. 8 von 1871 einen Verweis. Der beschuldigte Unterbezirksrichter verteidigte sich in einer langen Rede und verlangte einen Freispruch. In seinem Plädoyer berief er sich auf die richterliche Unabhängigkeit und wiederholte öfters, dass er „,trotz der präsidentiellen Ermahnungen weiterhin genauso verfahren werde wie bisher, denn sein Stolz befehle es ihm so" ${ }^{39}$

Das Tafelgericht wertete den Eifer und den Fleiß des Unterbezirksrichters als Strafmilderungsgrund und verhängte lediglich eine Rüge. Gegen das Urteil legte Laczkó Berufung ein. Am 23. April 1904 sprach ihn die Kurie von der Beschuldigung, ein Disziplinarvergehen begangen zu haben, frei.

\section{Der fidele Bezirksrichter}

Im Herbst 1930 wurde Károly Balog, Bezirksrichter zu Sollnock (Szolnok) beschuldigt, als Witwer eine längere Zeit im Gebäude des Bezirksgerichts zu Sollnock, später in der Stadt, in einer Wohnung mit einer Frau zusammen gewohnt zu haben, von der er vor seinen Richterkollegen und auch vor anderen Leuten behauptete, sie sei seine Schwester. Der Bezirksrichter „führte ein unanständiges, zu lautes Nachtleben“, indem er tanzte und mit der Frau sogar „völlig unbekleidet schäkerte“. Da aber die Wohnungsfenster auf das Gebäude des Bezirksgerichtsgefängnisses schauten,

\footnotetext{
${ }^{38}$ Egy bíró fegyelmi ügye 12.

39 Rosszallásra ítélt bíró 8 .
}

gaben seine skandalösen Ausschweifungen Anlass zum Gerede unter den Gefängnisinsassen.

Als ihn der Vorsitzende des Gerichtshofs zur Verantwortung zog, erklärte er, die Frau sei seine Nichte; erst später gestand er, dass sie seine Freundin sei, und versprach, die Frau „aus seiner Wohnung zu entfernen“. Dazu kam es jedoch nicht. Daraufhin zog ihn der Vorsitzende des Budapester königlichen Tafelgerichts zur Verantwortung. Balog wies die Beschuldigung mit der Begründung zurück, „über mein Privatleben bin ich keine Rechenschaft schuldig". Später versprach er jedoch, die mit ihm im gemeinsamen Haushalt lebende Frau bis zum 1. April $1930 \mathrm{zu}$ heiraten. Aber er löste auch dieses Versprechen nicht ein.

Laut Anklageschrift wurde Károly Balog „des seiner Stellung gebührenden Ansehens und Vertrauens unwürdig“, denn ein Richter ,darf moralische Gesichtspunkte auch in seinem Privatleben niemals aus den Augen verlieren". Der Disziplinarsenat des Budapester königlichen Tafelgerichts verhängte nach einer langen Verhandlung einen Verweis sowie eine Versetzung. ${ }^{40}$

\section{Der Fall des der Verletzung seiner Amtspflichten beschuldigten Richters am Gerichtshof und des Notars}

István Pancera, der mit dem Titel und dem Amt eines Richters am königl. Tafelgericht bekleidete Richter am königlichen Gerichtshof zu Fiume [Rijeka] geriet im März 1912 nicht das erste Mal in den Mittelpunkt der Aufmerksamkeit in Fiume, da er damals schon seit Jahren einen „verzweifelten Kampf" gegen den dortigen Notar György Fésűs führte. Dieser beschuldigte ihn nämlich schwerwiegender Sachen, und Pancera strengte gegen ihn sogar eine Verleumdungs-

\footnotetext{
${ }^{40}$ Bíróhoz nem illő életmód 4.
} 
klage an. In der Sache ging der Budapester königliche Strafgerichtshof als delegiertes Gericht in erster Instanz vor.

Die Vorwürfe des Notars bezogen sich teils auf die Amtstätigkeit, teils auf das Privatleben des Richters. Die Zeugenaussagen bestätigten die Vorwürfe. Es bewahrheitete sich, dass Pancera seine Amtspflichten nachlässig und ungenau erfüllte. Seine Gerichtsschreiber vernahmen in seiner Abwesenheit die Parteien unter Eid, außerdem führten sie sogar gerichtliche Augenscheine durch, deren Protokolle der Richter nachträglich, ohne Kenntnisse über ihre Richtigkeit und ihren Wahrheitsgehalt, unterzeichnete. Es kam auch vor, dass er die „verknoteten“ Prozesse erst nach 9-10 Monaten „Liegenlassen“ erledigte. Der Strafgerichtshof stellte fest, dass der Richter durch seine Nachlässigkeit im Amt sogar mehrmals die Tatbestände der im Gesetz Nr. 8 von 1871 bestimmten Disziplinarvergehen verwirklicht hatte.

Auch das Privatleben des Richters „rief die strengste Kritik hervor", denn er spielte Tag für Tag an öffentlichen Orten, in Kaffeehäusern Glücksspiele - um sein Einkommen zu vermehren -, und er hatte seit fast 20 Jahren den Ruf in Fiume, ein bekannter Falschspieler zu sein.

Bei der Strafzumessung fand das Gericht keinen erschwerenden Umstand zum Nachteil von György Fésüs. Als strafmildernd wurde bewertet, dass der Angeklagte die Verleumdung im öffentlichen Interesse, „im Zuge der Verteidigung seiner berechtigten Privatinteressen und seiner Reputation als Notar begangen" habe. Fésüs wurde vom Strafgerichtshof zu einer Geldstrafe von 700 Kronen verurteilt. ${ }^{41}$

In zweiter Instanz wurde die Sache im September 1912 vor dem Budapester königlichen Tafelgericht verhandelt. Das Tafelgericht sprach György Fésüs frei und begründete den Freispruch wie

\footnotetext{
${ }^{41}$ A Fésűs-Pancera ügy 14-15.
}

folgt: Es sah die Behauptung, die zum Gegenstand der Anklage geworden war, als bewiesen an. Der Behauptung nach verletzte István Pancera seine richterlichen Amtspflichten schwer, insbesondere dadurch, dass er mit den Verhandlungen, Zeugenvernehmungen und Vereidigungen seine Gerichtsschreiber, fallweise sogar Praktikanten beauftragte, außerdem ,seinen Sitz ohne Erlaubnis verließ“. Das Gericht der zweiten Instanz befand als feststehende Tatsache, dass Richter Pancera mit größeren Einsätzen an öffentlichen Orten wiederholt Hasard spielte. Fésüs nahm das Urteil an, aber der Staatsanwalt und Pancera legten Nichtigkeitsbeschwerde gegen das Urteil ein. Die Kurie bestätigte im November 1913 das Urteil der zweiten Instanz.

Es ist interessant an der Sache, dass gegen István Pancera auf Grund der im Verleumdungsprozess bestätigten Anschuldigungen ein Disziplinarverfahren eingeleitet wurde, das am 8 . November 1913 mit Freispruch endete. Die Entscheidung ließ dem Notar Fésüs keine Ruhe, und er veröffentlichte in mehreren Tageszeitungen eine Erklärung, in der er alle Unterlassungen und Pflichtverletzungen des Richters Pancera Punkt für Punkt auflistete, die in den erst- und zweitinstanzlichen rechtskräftigen Urteilen festgehalten worden waren. „Warum aber die Kurie trotz all dieser, gerichtlich festgestellten Tatsachen István Pancera doch freigesprochen hat, weiß ich nicht", schloss er seine Erklärung. ${ }^{42}$

Nach dem Freispruch durch das Disziplinargericht wurde István Pancera - auf sein eigenes Verlangen - an den königlichen Gerichtshof zu Großkirchen (Nagykanizsa) versetzt. Er ließ die skandalösen Jahre in Fiume hinter sich und wurde zu einem angesehenen Bürger der Stadt Großkirchen.

Das Richterdisziplinargesetz von 1871 wurde mit geringfügigen Änderungen und Ergänzungen bis zum Inkrafttreten des Gesetzes Nr. 3 von 1936

42 Pancera úr - feddhetetlen 13. 
über die disziplinäre Verantwortlichkeit, Versetzung und Pensionierung von königlichen Spruchrichtern und Mitgliedern der königlichen Staatsanwaltschaft sowie über die disziplinäre Verantwortlichkeit von Beamten der königlichen Gerichte und Staatsanwaltschaften angewendet.

\section{Korrespondenz:}

Univ.-Doz. Dr. Kinga Beliznai BóDi Ph.D.

ELTE Eötvös-Loránd-Universität

Staats- und Rechtswissenschaftliche Fakultät

Lehrstuhl für Ungar. Staats- und Rechtsgeschichte

Egyetem tér 1-3

$\mathrm{H}$ - 1056 Budapest

beliznai.kinga@ajk.elte.hu

ORCID-Nr. 0000-0003-3420-2260

\section{Abkürzungen:}

Siehe das allgemeine Abkürzungsverzeichnis: [http://www.rechtsgeschichte.at/media/abk.pdf]

\section{Literatur:}

A bírói felelősség rendszere [System der richterlichen Verantwortlichkeit], in: Jogtudományi Közlöny [Rechtswissenschaftliche Mitteilungen], Nr. 50 v. 14. 12. $1888,406-407$.

Béla CsÁNK, A bírói függetlenség hazánkban és külföldön [Die richterliche Unabhängigkeit im unseren Land und im Ausland] (Budapest 1942).

Károly CSEMEGI, A bírói fegyelmi törvény és a bírói függetlenség [Das Richterdisziplinargesetz und die richterliche Unabhängigkeit], in: Károly EDVI ILLÉS, Zsigmond GYOMAI (Hgg.), Csemegi Károly művei [Werke von Károly Csemegi], Bd. I (Budapest 1904).

Henri François D'AGUESSEAU, La censure publique (Deuxième Mercuriale), in: Jean-Marie PARDESSUS (Hg.), Evres completes du chancelier d'Aguesseau, Bd. I (Paris 1819).
Ludwig GuMPLOWICZ, Das Österreichische Staatsrecht. Verfassungs- und Verwaltungsrecht (Wien 1907).

Konrád IMLING, Észrevételek a bírák és bírósági hivatalnokok felelősségéről szóló törvényjavaslatra [Bemerkungen zur Gesetzvorlage über die Verantwortlichkeit von Richtern und richterlicher Beamten], in: Jogtudományi Közlöny [Rechtswissenschaftliche Mitteilungen], Nr. 48 v. 30. 11. 1888 , 389-390.

Gerald KOHL, Richter in der Habsburgermonarchie, in: DERS., Ilse ReITER-ZATLOUKAL (Hgg.), RichterInnen in Geschichte, Gegenwart und Zukunft. Auswahl, Ausbildung, Fortbildung und Berufslaufbahn (Wien 2014) 63-82.

Gerald KOHL, Zur Entwicklung der richterlichen Unabhängigkeit bis zum Bundes-Verfassungsgesetz 1920, in: Barbara Helige, Thomas OleCHOWSKI (Hgg.), 100 Jahre Richtervereinigung. Beiträge zur Juristischen Zeitgeschichte (Wien 2007) 9-26.

Gábor MÁTHÉ, A magyar burzsoá igazságszolgáltatási szervezet kialakulása 1867-1875 [Entwicklung der ungarischen bürgerlichen Gerichtsorganisation 1867-1875] (Budapest 1982)

Miksa SzÉKELY, A bírák és bírósági hivatalnokok felelősségéről szóló törvényjavaslat [Gesetzvorlage über die Verantwortlichkeit von Richtern und richterlichen Beamten], in: Magyar Jogászegyleti Értekezések [Abhandlungen des Ungarischen Juristenvereins], Bd. XLIII. V. 2 (Budapest 1889).

\section{Zeitungen:}

A „szegedi cikk”. Egy táblabíró fegyelmi ügye [Der "Szegediner Artikel". Disziplinarangelegenheit eines Richters beim Tafelgericht], in: Pesti Hírlap [Pester Nachrichtenblatt] Nr. 128 v. 8. 5. 1892, 11.

A Fésűs-Pancera ügy [Die Fésűs-Pancera-Angelegenheit], in: Budapesti Hírlap [Budapester Nachrichtenblatt] Nr. 76 v. 29. 3. 1912, 14-15.

A járásbíró találmánya [Erfindung eines Bezirksrichters], in: Budapesti Hírlap [Budapester Nachrichtenblatt] Nr. 72 v. 22. 3. 1908, 20.

Amtlicher Theil, in: Wiener Zeitung Nr. 10 v. 12. 1. 1861, 141. 